\title{
Household energy, indoor air pollution and child respiratory health in South Africa
}

\author{
Brendon Barnes \\ School of Human and Community Development, University of the Witwatersrand; and \\ Environment and Health Research Unit, Medical Research Council of South Africa
}

Angela Mathee

Environment and Health Research Unit, Medical Research Council of South Africa

\section{Elizabeth Thomas}

Centre for Health Policy, School of Public Health, University of the Witwatersrand; and

Medical Research Council of South Africa

\section{Nigel Bruce}

Department of Public Health, University of Liverpool, England

\begin{abstract}
Indoor air pollution due to the indoor burning of polluting fuels has been associated with Acute Lower Respiratory Infections (ALRI) amongst children less than five years old. This paper reviews evidence of the association between household energy, indoor air pollution and child ALRI in South Africa. Studies show evidence consistent with the international literature with the likelihood of ALRI between 2 and 4 amongst children living in households using polluting fuels compared to households using electricity. Indoor air pollution is responsible for the deaths of up to 1400 children annually. Interventions have demonstrated $46-97 \%$ lower pollution concentrations compared to open fires. However, the sustainability of selected interventions has been questioned in certain contexts. The paper discusses the strengths and weaknesses of the evidence and highlights opportunities for further research.

Keywords: household energy, indoor air pollution, child ARI, interventions
\end{abstract}

\section{Introduction}

Over half the global population (3 billion people) are reliant on solid biomass fuels such as wood, coal, crop residues and animal dung for their domestic energy requirements (The World Rsources Institute, 1998; Ezzati et al., 2004). When burned indoors in open fires or rudimentary appliances, the incomplete combustion of solid biomass fuels release high concentrations of toxic pollutants such as particulate matter (PM), carbon monoxide (CO), oxides of nitrogen, sulphur dioxide $\left(\mathrm{SO}_{2}\right)$ and volatile organic compounds into the living environment (Smith, 1987; Bruce et al., 2000). In addition to environmental concerns such as deforestation and greenhouse emissions, the high household reliance on solid biomass fuels has been associated with a number of health outcomes.

Exposure to indoor air pollution has been associated with chronic obstructive pulmonary disease, lung cancer, nasopharyngeal cancer, tuberculosis and diseases of the eye in adults; low birth weight and, of particular concern, acute lower respiratory infections (ALRI) such as pneumonia amongst children less than five (Bruce et al., 2000; Smith et al., 2000). ALRIs are the single leading cause of death amongst children less than 5 years old worldwide 
(Murray and Lopez, 1997) and amongst the top 4 killers of South African children less than five years old (von Schirnding et al., 1991b; Bradshaw et al., 2003).

Young children are more susceptible to ALRI through indoor air pollution exposure for a number of reasons. The epithelial linings of children's lungs are not fully developed resulting in greater permeability of pollutants (Pande, 2000), their immune systems are not fully developed thereby limiting the body's defence against infection (Smith et al., 2000), they have higher respiration rates and they have a larger lung surface area per kilogram of body weight thus breathing in approximately $50 \%$ more (polluted) air under normal breathing conditions compared to adults (Moya et al., 2004). In addition, from an exposure perspective, children tend to follow their caregivers' around, for example, through carriage on their caregivers' backs (Mtango et al., 1992).

Indoor air pollution exposure is a function of the complex interplay between household fuel patterns (Smith, 1987), appliances (Ezzati et al., 2000), housing design (Bruce et al., 2002) and human behaviour (Barnes, 2005). In addition, risk factors such as nutrition, crowding, family history of infection, poor vaccination history and exposure to environmental tobacco smoke (Kirkwood et al., 1995; Victora et al., 1994) may influence child susceptibility to ALRI. Even more challenging is the fact that indoor air pollution unravels against the backdrop of poverty that influence each of these factors.

In terms of global relevance, South Africa is particularly interesting for two reasons. Firstly, there have been a number of scientific studies (summarized in this paper) to understand the problem of indoor air pollution and child ALRI in South Africa. Secondly, there have been a number of postapartheid policy developments - including the Clean Air Act (NEM 2004) and the Integrated National Electrification Programme (INEP) - that have been designed to address, amongst others, indoor air pollution. The problem, however, is that except for one review of the methodological quality of epidemiological studies (Wichmann \& Voyi, 2005), the scientific evidence has yet to be integrated into a single review document.

The aim of this paper, therefore, is to review the scientific evidence of the association between household energy, indoor air pollution and child ALRI in South Africa. In terms of methodology, studies were sourced using the PubMed, Google Scholar and Electronic Theses and Dissertation (ETD) databases. Search terms included the following: South Africa, household energy, indoor air pollution, child ALRI, epidemiology, wood smoke, interventions and poverty. Overall, 68 works were sourced based on their relevance to the topic. Peerreviewed journal articles, peer reviewed reports and dissertations were prioritised for review, which means that (important) topics such as renewable energy and housing efficiency that are under represented from an indoor air pollution perspective in the published peer-reviewed literature receive limited attention. Before proceeding, it is important to understand the spatial and temporal patterns of household energy in South Africa.

\section{Household energy patterns}

The 'energy ladder' model has been used to categorise energy sources along a hierarchy according to their cost, ease of use, technological advancement and, importantly for this work, the concentrations of air pollution they produce (Smith et al., 1994). At the bottom of the ladder are solid biomass fuels such as cow dung, crop residues and wood. Biomass fuels are followed by coal, charcoal and paraffin (often referred to as transition fuels). 'Modern fuels' such as liquid petroleum gas (LPG), natural gas and electricity occupy the higher rungs of the ladder. Electricity is situated at the top of the ladder and is considered to be the safest fuel in terms of indoor air quality. As fuels become more advanced and safer, however, they also increase in both direct (to use them) and indirect (to purchase appliances to use them) cost at the household level (Smith, 1987).

The South African government's household energy strategy has had a strong focus on household electrification (http://www.dme.gov.za/energy/elect_inep/stm). The INEP electrified over 2.5 million households between 1994 and 2000 at a rate of approximately 1000 households per day. As a result, between 1994 and 1999, the proportion of households with access to electricity increased from a $36 \%$ to $63 \%$ (Department of Minerals and Energy, 2001). By the end of 2006, 73\% of South African households had access to electricity (Department of Minerals and Energy, 2006).

Table 1 summarizes the main energy used for cooking and space heating derived from Statistics South Africa's 1996 and 2001 census as well as 2007 community survey data sets. Electricity was the main fuel used for cooking and heating followed by either paraffin or wood at each interception. It is encouraging to note that there was a marked increase in the proportion of households using electricity for cooking $(+20 \%)$ and heating $(+14 \%)$ between 1996 and 2007; gas remained relatively static; while there were decreases in paraffin $(-7 \%$ for cooking and $-1 \%$ for heating), wood $(-7 \%$ for cooking and $-8 \%$ for heating) and coal (-3\% for cooking and $-4 \%$ for heating) (Statistics South Africa, 1998, 2003 and 2007).

Movement up the energy ladder was particularly noticeable amongst the Black African ${ }^{1}$ population group, which due to apartheid legislation was, and continues to be, the most underserved social group 
Table 1: South African fuel use 1996-2007

Source: Statistics South Africa (1998, 2003 \& 2007)

\begin{tabular}{|c|c|c|c|c|c|c|}
\hline \multirow[b]{2}{*}{ Year } & \multicolumn{3}{|c|}{ Main fuel used for cooking } & \multicolumn{3}{|c|}{ Main fuel used for heating } \\
\hline & 1996 & 2001 & 2007 & 1996 & 2001 & 2007 \\
\hline Electricity & 47 & 51 & 67 & 45 & 49 & 59 \\
\hline Gas & 3 & 3 & 2 & 1 & 1 & 1 \\
\hline Paraffin & 21 & 21 & 15 & 14 & 15 & 13 \\
\hline Wood & 23 & 21 & 15 & 27 & 25 & 20 \\
\hline Coal & 4 & 3 & 1 & 8 & 7 & 4 \\
\hline Animal dung & 1 & 1 & $<1$ & $<1$ & $<1$ & $<1$ \\
\hline
\end{tabular}

in terms of energy access. Electricity as the main fuel used increased by $8.9 \%$ for cooking and $9.3 \%$ (between 1996 and 2001) for heating amongst this group - possibly a function of improved access to electricity the INEP together with an improvement in household income to be able to afford that electricity.

While the Statistics South Africa datasets provide a useful overview of household energy patterns, the figures tend to mask the use of multiple fuels for cooking and heating purposes. The census data is derived from a question that focused on the main fuel used for cooking and heating. In reality, however, poorer households use multiple fuels to fulfil their domestic energy needs based largely, although not exclusively, on their ability to afford those fuels (Davis, 1998; Shackleton, Gambiza \& Jones, 2007).

Figure 1 highlights access to electricity as well as solid biomass fuel use in South Africa. Data is disaggregated by rural-urban differences but also, importantly, by level of economic development (reported as wealth quintiles) (WEC \& FAO, 1999). In urban contexts, access to electricity increases and biomass usage decreases with economic development. Put simply, wealthier urban households not only have better access to electricity but also use that electricity for their domestic energy needs. In rural contexts, however, not only is electricity access poorer but fuel switching is more commonplace, that is, the combined use of electricity with other (usually) biomass fuels.

Multiple fuel use has been highlighted by a number of localised studies that have focused on household energy patterns. A study in the rural North West Province (Mathee et al., 2000), for example, found that after electrification, all households used electricity immediately for lighting (the cheapest function). Approximately $44 \%$ and $89 \%$ of households had never used electricity for cooking and heating respectively three years after being electrified. The effect of household economic development was also highlighted in a study of 1000 households in Port Elizabeth (Thomas et al., 1999). Although most households were electrified, amongst the low quintile group only $19.3 \%$ of households were reliant on electricity for cooking purposes followed by the lower middle (36\%), middle $(83.6 \%)$ and upper middle $(94.3 \%)$ quintile. Amongst the high wealth quintile, $99.5 \%$ of households were reliant on electricity for cooking. Paraffin was used as the secondary fuel with a small proportion of households reliant on LPG $(<3 \%)$ in each category (Thomas et al., 1999).
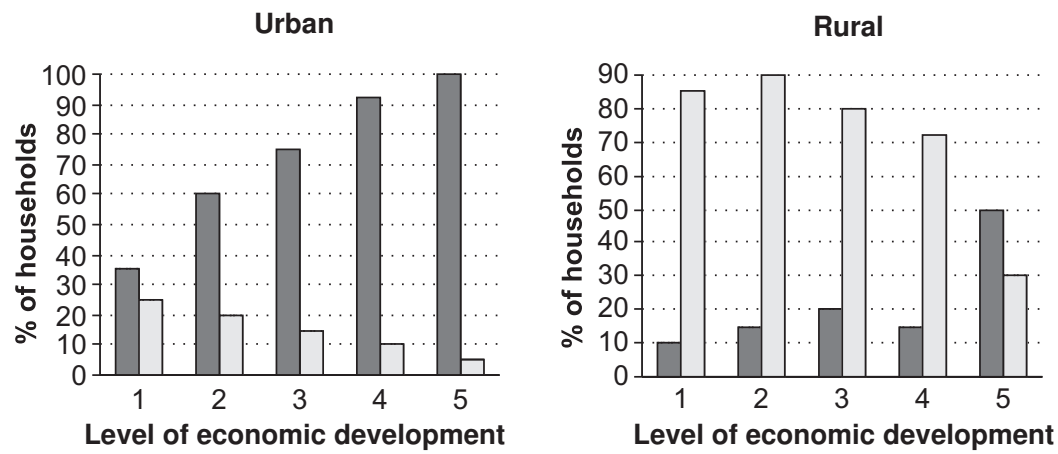

Electrified $\square$ Solid biomass use

Figure 1: Household energy patterns by level of economic development in South Africa Source: WEC \& FAO (1999) 
Paraffin remains a major concern in poor urban environments not only from an indoor air quality perspective, but also because of its association with child poisoning and property damage (Matzopoulos, Jordaan \& Carolissen, 2006). Paraffin dependence is supported by several studies in poor urban settlements. A study in Cato Manor (Durban), for example, found that $87 \%$ of households were reliant on paraffin for cooking (Muller et al., 2003), while a study in Alexandra (Johannesburg) found that $52 \%$ of households were reliant on paraffin for cooking (De Wet et al., 2001). A multi-site survey found a high reliance on paraffin even after electrification in Lady Grey (North Eastern Cape) $(90 \%$ of households relied on paraffin), Benoni (Gauteng) (73\%), Gugulethu (Western Cape) (73\%) and Galashewe (Northern Cape) (56\%) (Roberts \& Wentsel, 2006).

Coal continues to be heavily used in high density urban settlements. Although household coal reliance is relatively low at the national level ( $3 \%$ for cooking and 7\% for space heating in 2001), the problem is highly localised (Statistics South Africa 2003). For example, over $63 \%$ of households in informal settlements in the 'Vaal Triangle' areas of Sasolburg, Vereeniging and Vanderbijlpark are reliant on coal. Pollution from coal is not only a problem from indoor air pollution (particularly for adult health outcomes such as lung cancer) but also its contribution to community air pollution especially during winter.

In sum, although access to electricity has significantly increased from 1994, poorer communities continue to rely on polluting fuels as secondary energy sources. In rural areas wood is still widely used while in urban areas paraffin remains a popular choice. The high reliance on polluting fuels, particularly amongst poorer South African households, raises the question: what are the respiratory health effects of indoor air pollution exposure? To answer this question, we review the epidemiological evidence of the association between indoor air pollution and child ALRI.

\section{Epidemiological evidence}

Although epidemiological studies of the health effects of indoor air pollution exposure in South Africa are limited, several studies have highlighted cause for concern. As early as 1982, Kossove found that of 132 infants with severe lower respiratory tract disease treated in an outpatient clinic, $70 \%$ were exposed to daily levels of smoke from cooking and heating. In comparison only $33 \%$ of the 18 infants free of respiratory illness were exposed to smoke (Kossove, 1982) $(\mathrm{OR}=4.2)$.

Similarly, household reliance on solid fuels such as wood, coal and cow dung has been associated with child ARI morbidity. Amongst others, a failure to use electricity for cooking and heating was found by von Schirnding et al., (1991a) $(\mathrm{OR}=2.5)$ and Dudley et al., (1997) $(\mathrm{OR}=2.37)$. In addition, one study found that chest illness amongst children (particularly boys) was strongly associated with non electricity fuel use (Zwi et al., 1990) ( $O R=1.88)$. Sanyal and Maduna (2000) showed a possible association between high levels of recurring respiratory symptoms amongst children and high levels of indoor air pollution (up to 12 times international guidelines) amongst poor communities living in the Eastern Cape province of South Africa.

One of the most comprehensive South African studies - the Vaal Triangle Air Pollution Study (VAPS) - highlighted, amongst others, high levels of air pollution in coal burning urban areas as well as the risk to upper and lower respiratory health associated with exposure (Terblanche et al., 1992; Terblanche et al., 1993). Amongst rural children, the VAPS study also highlighted a significantly elevated risk of developing $\mathrm{ARI}(\mathrm{OR}=5)$ amongst children in wood and coal burning homes (Nel et al., 2003). Although in a positive direction $(\mathrm{OR}=1.3)$, a study by (Wesley \& Loening, 1996), however, showed no significant association between fuel use on the severity of respiratory infections.

More recently, the work of Wichmann and Voyi focused on the association between polluting fuels and child ALRI derived from the 1998 South African Demographic and Health Survey ( $\mathrm{n}=12$ 000 households). In terms of morbidity, children who lived in households that burned polluting fuels were 1.27 times more likely to have experienced an ALRI episode in the two weeks preceding the interview compared to children living in homes using clean fuels (defined as LPG or electricity) (Wichmann \& Voyi, 2006a). The relative risk for mortality was 1.95 after adjusting for potential confounding (Wichmann \& Voyi, 2006b). The associations (presented as odds ratio with 95\% confidence intervals) found in the epidemiological studies considered in this paper are summarized in Figure 2.

A number of indoor air quality studies - that have not necessarily reported on child respiratory health - have highlighted cause for concern. A study of indoor air quality among 72 paraffin burning urban households revealed that $42 \%$ of households exceeded one hour guidelines for $\mathrm{SO}_{2}, 30 \%$ for $\mathrm{CO}$ and $9 \%$ for $\mathrm{NO}_{2}$ (Bailie et al., 1999). Similarly, Sanyal and Maduna (2000) found that levels of $\mathrm{CO}, \mathrm{SO}_{2}$ and $\mathrm{NO}_{2}$ often exceeded accepted guidelines in a peri-urban setting in the Eastern Cape. Monitoring of $\mathrm{PM}_{10}$ amongst 100 household in the rural North West Province during winter showed that $68 \%$ of wood and cow dung burning households exceeded the US EPA (24 hour) guideline of $150 \mu \mathrm{g} / \mathrm{m}^{3}$ for $\mathrm{PM}_{10}$ (Barnes et al. 2006). The study also showed that children were in the kitchen $52-61 \%$ of the total time that a fire was burning during winter (Barnes et al., 2005). 


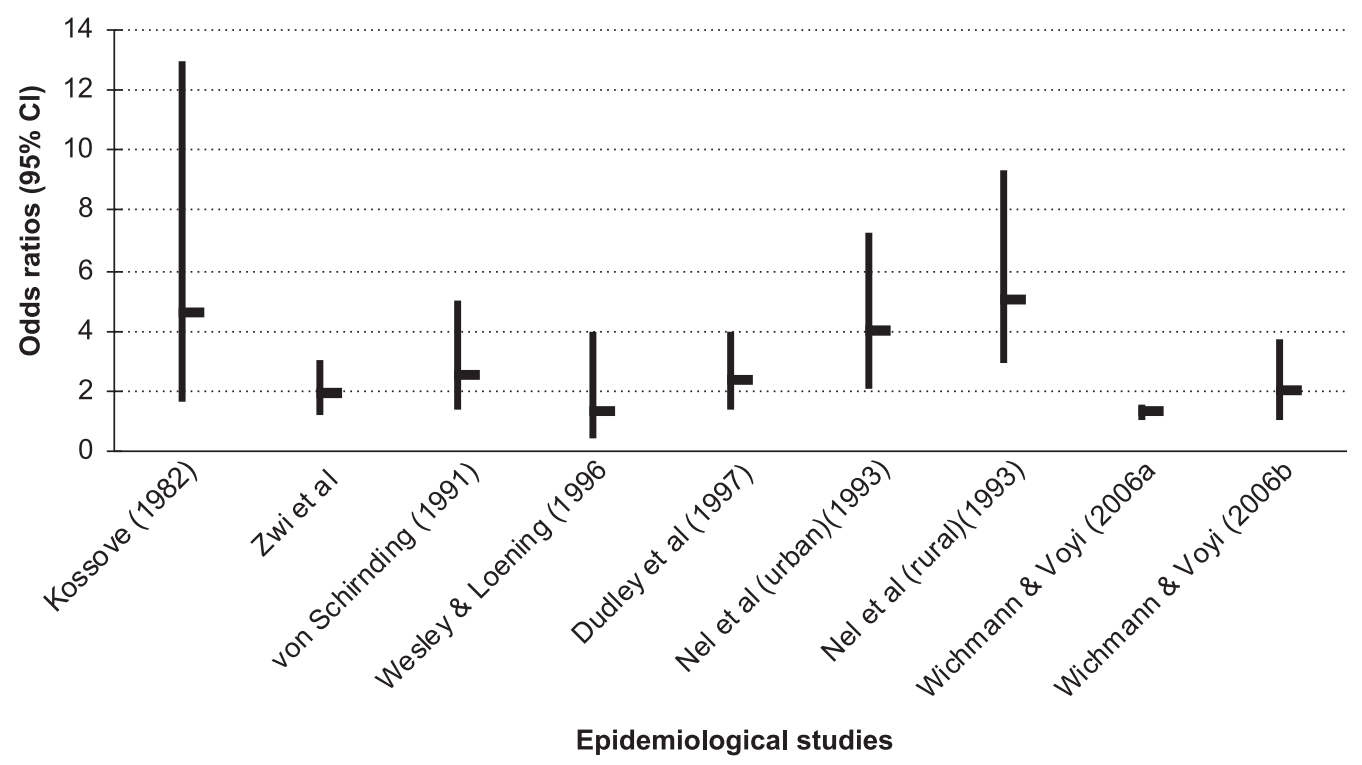

Figure 2: Risk of child ALRI and polluting fuels in South Africa

Air quality studies have also demonstrated a strong seasonal trend in indoor air pollution because of the increased reliance on solid fuels for space heating. The study by Sanyal and Maduna (2000) showed a strong seasonal trend with $\mathrm{CO}$, $\mathrm{SO}_{2}$ and $\mathrm{NO}_{2}$ significantly lower in summer compared to winter. Amongst the low income group (mostly reliant on wood and low-grade coal), morning average hourly $\mathrm{CO}$ sampled in the cooking area increased by $63 \%$ while $\mathrm{NO}_{2}$ increased by $130 \%$. Compared to summer, a study in a coal burning township in the VAPS showed a $101 \%$ increase in children's $(8-12$ years old) total suspended particulate (TSP) exposure during summer (Terblanche et al., 1993). Similarly, a comparison of two studies conducted in the same rural un-electrified villages and using the same sampling methodology - one in summer (Röllin et al., 2004) and one in winter (Barnes et al., 2006) - showed a difference of $\mathrm{PM}_{10}$ measured in kitchens of over $200 \%$.

Based on these and other studies, the World Health Organization (WHO) has recently estimated that 1000 people die annually from indoor air pollution exposure in South Africa. Of these, 450 children die of ALRI as a result of indoor air pollution exposure (World Health Organization, 2007). However, burden of disease estimates (BOD) done by the South African Medical Research Council suggests that indoor air pollution caused substantially more (2 489) deaths in South Africa that included 1 428 children less than five years old who died of ALRI because of indoor air pollution exposure (Norman et al., 2007).

Given the strength of the associations between indoor air pollution exposure and child ALRI, it is important to understand the effectiveness of potential prevention activities. The following section reviews studies of the effectiveness of indoor air pollution prevention.

\section{Potential interventions}

Globally, four intervention categories have been identified for their potential to reduce the impact of indoor air pollution on child ALRI: cleaner burning fuels, improved cook stoves, housing design and behavioural change (Ballard-Tremmer \& Mathee, 2000; von Schirnding et al., 2002). Six South African studies have highlighted the potential role of prevention interventions in reducing indoor air pollution.

In terms of cleaner burning fuel, a study by Röllin et al., (2004) showed that, despite slow household progression up the energy ladder, rural electrified households showed $75 \%$ lower $\mathrm{PM}_{10}$ (24 hour) concentrations than similar un-electrified households. One South African study monitored outdoor air pollution close to the living environment for 30 days before and after the introduction of household low-smoke fuels in an urban community. Air pollution was highest when low-grade coal was used in households during the first ten days of the experiment (mean daily $\mathrm{PM}_{10}$ concentrations equalled $129 \mu \mathrm{g} / \mathrm{m}^{3}$ ), were lowest after low smoke fuels were introduced over the next ten days (mean equalled $\left.70 \mu \mathrm{g} / \mathrm{m}^{3}\right)$ (46\% reduction) and increased again after residents used a combination of low grade coal and low smoke fuels over the final ten days (mean equalled $86 \mu \mathrm{g} / \mathrm{m}^{3}$ ). Although the study only measured outdoor air pollution, it highlighted the potential of low smoke coal in reducing indoor air pollution (Engelbrecht et al., 2001).

Ballard-Tremeer \& Jawurek (1996) compared the emissions of fuel/appliance combinations under controlled laboratory settings. The study showed 
benefits from modern fuels such LPG and paraffin under controlled burning conditions. The simple act of raising a solid fire by placing it on a grate a few centimetres off the ground showed a $41 \%$ reduction in indoor air pollution while a 2-pot ceramic stove reduced emissions by $44 \%$ (Ballard-Tremeer \& Jawurek, 1996). Importantly, the study showed that the 1-pot and 2-pot metal stoves emitted more pollution than the open fire highlighting and the fact that it is important to be cautious about assuming that improved technology will necessarily result in lower emissions.

A laboratory study by Surridge et al., (2005) focused on the impact of an alternative ignition process for coal fires on indoor air quality. The study reported that the upside-down ignition method in a commonly used burning appliance in urban South Africa (the brazier or 'mbawula') where fires are ignited with coal at the bottom, paper/wood kindle above the coal and a small amount of coal on top (instead of the regular method of paper/wood kindle at the bottom and coal at the top) - reduced $\mathrm{PM}_{10}$ by $80-90 \%$ in laboratory testing (indoor air pollution levels, however, were not reported), took a shorter time to cook with and less coal being used (Surridge et al., 2005). The 'Basa Njengo Magogo' (which, translated means 'make your fire like the old lady' is based on the idea was perfected by an old lady in a pilot phase) project has been included in South Africa's Integrated Household Clean Energy Strategy.

A before-intervention study in the rural North West Province promoted the health benefits of outdoor burning amongst poor rural (un-electrified) communities. When fires were brought indoors, the intervention promoted safer ventilation and child location practices. Based on two phases of formative research (Barnes et al., 2004b; Barnes et al., 2004a), the study showed that household shifts to outdoor burning was associated with significantly lower median levels of indoor air pollution $\left(\mathrm{PM}_{10}\right.$ by $94-96 \%$ and CO by $85-97 \%$ ) and child personal exposure to CO $(83-95 \%)$ compared to indoor burning. Behaviours in the indoor environment e.g. opening windows when fires were burning was associated with a $50 \%$ median reduction in pollutant concentrations (Barnes et al., 2006). Figure 3 summarizes pollutant reductions associated with the interventions described above.

\section{Discussion}

It is encouraging to note the progression of the South African population up the energy ladder between 1996 and 2007. Importantly, there was a higher than average increase amongst Black African households who used electricity as the main fuel used for cooking and heating. The use of electricity has been associated with a significant decrease in indoor air pollution (Röllin et al., 2004) and found

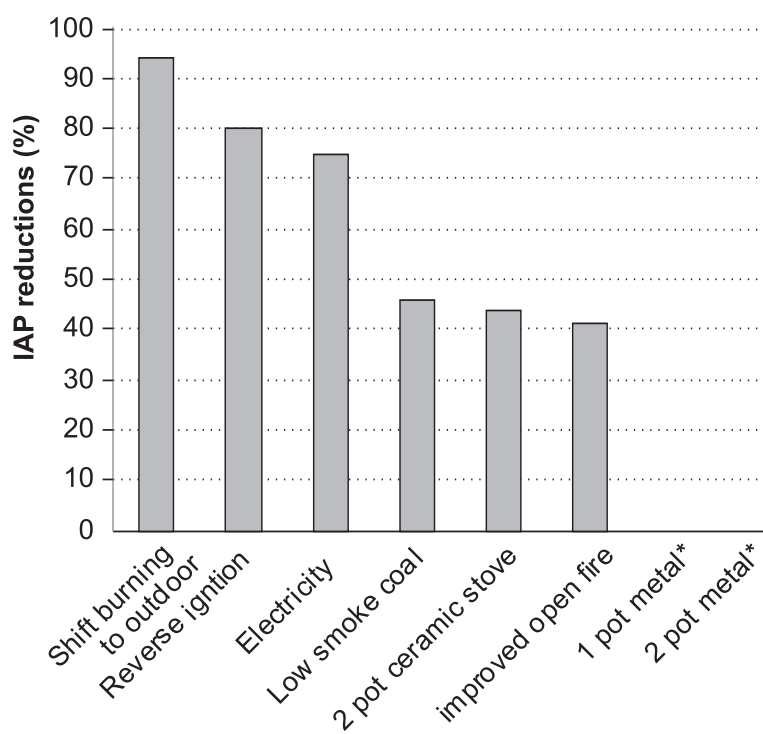

* Increased pollutant concentrations compared to open fires

\section{Figure 3: Indoor air pollution reductions associated with interventions}

to be significantly protective of respiratory health (von Schirnding et al., 1991a; Dudley et al., 1997; Wesley \& Loening, 1996). Electricity access, however, does not necessarily imply a displacement of polluting fuels - particularly amongst the poor. The use of multiple fuels remains a concern after electricity (or other cleaner fuels) has been guaranteed.

Of particular concern is the continued dependence of paraffin in poor urban settlements. As much as $90 \%$ of poor households in informal settlements were reported to be dependant on paraffin as a secondary fuel after electricity has been guaranteed. Two studies (Bailie et al., 1999; Muller et al., 2003) have shown high levels of gaseous air pollution, which suggests that paraffin may not be as clean burning as previously thought (Mehta \& Shahpar, 2004). More work is needed to understand the health effects of indoor air pollution from paraffin burning.

Although South African epidemiological indoor air pollution studies are few, they are relatively consistent with the international evidence. The epidemiological studies reviewed in this paper showed positive associations between indoor air pollution and child ALRI. The majority of studies reported Odds Ratios (ORs) between 2 and 4, which are comparable to other studies in developing countries (ORs 2 - 3) (Smith, 2002; Dehrani et al., 2008). The high levels of indoor air pollution measured in South African households contribute to this concern. However, the body of South African epidemiological evidence has a number of limitations.

First, relatively few epidemiological studies have actually focused on indoor air pollution and child ARI in South Africa. For example, only eight published epidemiological studies could be sourced for 
this review. Second, very few studies have actually measured child indoor air pollution exposure or by the very least stationary indoor air concentrations. Instead, studies have mostly used proxies of exposure such as poor access to modern fuels, carriage on mothers' backs during cooking or estimates of the amount of time that children spend in the vicinity of fires to determine child indoor air pollution exposure (Ezzati \& Kammen, 2002; Smith, 2002).

Third, many studies have not adequately dealt with the role of confounding factors (Bruce et al., 1998). It is important to note that indoor air pollution is not the only risk factor for child ALRI. The association between indoor air pollution and child ALRI is complex and a number of factors are thought to influence the association including low birth weight, under nutrition, crowding, environmental tobacco smoke and incomplete immunization history (Victora et al., 1999; Victora et al., 1994; Kirkwood et al., 1995).

Fourth, South African indoor air quality studies have focused on different pollutants (e.g. $\mathrm{SO}_{2}, \mathrm{NO}_{2}$, $\mathrm{PM}_{10}$, CO and so forth) that have been measured over different time periods (1 hour, peak cooking times, 24 hours) using different sampling and analytic procedures (e.g. time weighted averages, passive diffusion sampling and/or continuous sampling), and have had different health outcome definitions (e.g. respiratory symptoms, incidence, severity and mortality). Despite the limitations, epidemiological studies and indoor air quality are supported by sophisticated air pollution studies in relation to outdoor pollution and exposure to environmental tobacco smoke (focusing on similar pollutants) conducted in developed countries (Schwartz, 2004)

South Africa is poised to address the indoor air pollution problem through a number of programmes such as the Integrated Household Clean Energy Strategy (IHCES) (Department of Minerals and Energy, 2004) and the ongoing Integrated National Electrification Programme (INEP) (Department of Minerals and Energy, 2001). In particular, the recently promulgated National Environmental Management: Clean Air Act No. 39 of 2004 (Statistics South Africa, 2004), under which indoor air pollution activities will be directed, calls for air quality management plans at the local, provincial and national levels to amongst others 'address the effects of emissions from the use of fossil fuels in residential applications' (NEM, 2004, 16 section (iv), p 20).

The effectiveness of a number of intervention strategies have been identified and tested in South Africa including electricity, low smoke fuels, improved cook stoves, reverse ignition and outdoor burning. Intervention studies suggest reductions of between $46-97 \%$ in the indoor environment typical of interventions documented in other develop- ing countries (Ballard-Tremmer \& Mathee, 2000; Budds et al., 2001). However, a comparison of these figures should be interpreted with caution. As mentioned above, studies have focused on different pollutants measured using different methodologies and conducted in a variety of settings (laboratory, field and so forth). In addition, the figures presented above reported percentage reductions compared to baseline values. This means that for some studies the baseline values to which reductions are compared are much higher than others. In addition, it is important to acknowledge the wide within-category variation of air pollutions values documented in developing countries, which means, for example, that well tended and ventilated indoor fires may have lower emissions than some improved technologies such as metal stoves (Ballard-Tremeer \& Jawurek, 1996).

When considering the effectiveness of interventions in reducing exposure, it is also important to be cautious about assuming that reductions will be of the magnitude to be statistically protective of child ALRI. As mentioned above, the relationship between child ALRI and indoor air pollution is complex and there are a number of reasons why there may be a positive yet relatively modest impact of exposure reductions on child ALRI. First, even though indoor air pollution is often significantly reduced, interventions often do not completely remove air pollution in the indoor environment. In some studies, residual indoor air pollution concentrations after intervention were still evident. The effectiveness of one intervention such as electricity may also be compromised by the use of one or more polluting fuels such as paraffin or solid fuels during winter. It is important, therefore, to acknowledge that interventions do not result in 'air pollution free' living environments and that even low levels of exposure together with other risk factors could still contribute negatively to child ALRI.

Second, as noted above, it is important to remember that the relationship between indoor air pollution and child ALRI is complex and a number of risk factors are thought to influence the relationship. Indeed, some of these factors are thought to play a much stronger role in child ALRI than indoor air pollution in certain contexts (Kirkwood et al., 1995). In South Africa, like elsewhere, indoor air pollution affects the poor where additional risk factors are particularly prevalent. While indoor air pollution may be significantly reduced, the magnitude of additional risk factors may serve to undermine any potential respiratory health gains.

Third, understanding the impact of interventions on child ALRI is also based on the assumption that the uptake and use of those interventions is sustained. Unfortunately, however, many factors serve to impede the uptake and sustainability of interventions in resource-poor settings. The successful dis- 
semination and uptake of interventions at the household level is generally context specific and is linked to a number of factors including the design of the intervention e.g. stove (to meet household domestic energy needs such as cooking and space heating), marketing strategies, subsidization, commercialization processes (including local job creation), user perceptions, community participation as well as local energy policies (Goldemberg, 2004; Barnes et al., 1994; Budds et al., 2001). In addition, the financial inability of poor households to afford the uptake and maintenance of the intervention remains a key concern.

Interventions cannot be selected based on pollution reducing effectiveness alone but also on the potential sustainability of those interventions suited to individual contexts. For example, in poor rural communities where fuels are collected free of charge and close to the living environment (the labour burden for fuel collection is low), it is highly unlikely that more expensive technologies such as electricity will be used in the short term. It is worthwhile considering a behavioural intervention approach in such contexts until households are able to afford such technologies. Similarly, in poor urban contexts, technologies to replace or improve paraffin stoves will need to fulfil a number of criteria including cost and convenience as well as addressing accessibility, local distribution and marketing. It is equally erroneous to assume that a single motivation - cost, convenience or improved health - is sufficient for the adoption of a given intervention. Factors that influence household energy choices are complex and what motivates households in one context to adopt an intervention may not be of value in another context. It is important, therefore, to have a thorough understanding of context specific factors that may influence not only effectiveness but also the uptake and sustainability of interventions.

A number of research gaps are evident in relation to household energy, indoor air pollution and health in South Africa. In particular, there is a need for larger more detailed studies to explore the association between interventions, indoor air pollution and, importantly, health impacts. Future studies need to monitor indoor air pollution and exposure for longer periods of time and in much more detail than previous studies (possibly continuously over the study period), need large enough sample sizes to be able to detect impacts on indoor air pollution as well as child ALRI, a clear case definition and robust methodology for diagnosing ALRI, and adjust for the myriad of confounding variables that may influence the impact of exposure reduction on child ALRI. If cases are to be measured at healthcare facilities, studies need to pay careful attention to care seeking behaviours, the accuracy and consistency of diagnosis as well as the quality of the records. There is also a need for harmonized methodologies to facilitate comparison of studies.

\section{Conclusion}

Indoor air pollution remains a major environmental health hazard for South African children. Despite the relatively small scale nature of the epidemiological evidence, South African studies have highlighted strong and relatively consistent associations between indoor air pollution and child ALRI. Children living in households that are reliant on polluting fuels are $2-4$ times more likely to suffer from an ALRI compared to children living in homes reliant on electricity resulting in as many as 1400 under fives death annually.

Interventions look promising in terms of reducing exposure. In particular, there is evidence of the progression up the energy ladder towards the exclusive use of electricity. There are contexts, however, where there may be a considerable delay in the uptake of electricity. Practitioners need to identify effective yet appropriate interventions to fill the gap until electricity is accessible and affordable.

\section{Note}

1. We use the term Black African to reflect a social category stipulated by apartheid legislation. In no way do we support the use of these racial categories except to highlight shifts in access to basic environmental health services from 1994 onwards (post apartheid era).

\section{References}

Bailie, R.S., Pilotto, L.S., Ehrlic, R.I., Mbuli, S., Truter, R. and Terblanche, P. (1999) Poor urban environments: use of paraffin and other fuels as sources of indoor air pollution. Journal of Epidemiology and Community Health 53, 585-586.

Ballard-Tremeer, G. and Jawurek, H.H. (1996) Comparison of Five Rural, Wood -Burning Cooking Devices: Efficiencies and Emission. Biomass and Bioenergy 11, 419-430.

Ballard-Tremmer, G. and Mathee, A. (2000) Review of interventions to reduce exposure of women and young children to indoor air pollution in developing countries. Washington D.C.: WHO/ USAID Global Consultation.

Barnes, B., Mathee, A., Bruce, N. and Thomas, L. (2006) Protecting children from indoor burning through outdoor burning in rural South Africa. Boiling Point 52, 11-13.

Barnes, B.R. (2005) Interventions to reduce child indoor air pollution exposure in developing countries: behavioural opportunities and research needs. Children, Youths and the Environment 15, 67-82.

Barnes, B.R., Mathee, A. and Moiloa, K. (2005) Assessing child time-activity patterns in relation to indoor cooking fires in developing countries: a methodological comparison. International Journal of Hygiene and Environmental Health 208, 219-225.

Barnes, B.R., Mathee, A., Shafritz, L.B., Krieger, L., 
Favin, M. and Sherburne, L. (2004a) Testing selected behaviours to reduce indoor air pollution exposure in young children. Health Education Research 19, 54350.

Barnes, B.R., Mathee, A., Shafritz, L.B., Krieger, L. and Zimicki, S. (2004b) A behavioural intervention to reduce child exposure to indoor air pollution: identifying possible target behaviours. Health Education and Behavior 31, 306-317.

Barnes, D.F., Openshaw, K., Smith, R.K. and Van der Plas, R. (1994) What makes people cook with improved cookstoves?

Bradshaw, D., Bourne, D. and Nannan, N. (2003) What are the leading causes of death among South African children? MRC Policy Brief

Bruce, N., Bates, E., Nguti, R., Gitonga, S., Kithinji, J. and Doig, A. (2002) Reducing indoor air pollution through participatory development in rural Kenya. Indoor Air 12, 590-595.

Bruce, N., Neufeld, L., Boy, E. and West, C. (1998) Indoor biofuel air pollution and respiratory health: the role of confounding factors among women in highland Guatemala. International Journal of Epidemiology $27,454-8$.

Bruce, N., Perez-Padilla, R. and Albalak, R. (2000) Indoor air pollution in developing countries: a major environmental and public health challenge. Bulletin of the World Health Organization 78, 1078-92.

Budds, J., Biran, A. and Rouse, J. (2001) What's Cooking: A review of the health impacts of indoor air pollution and technical interventions for its reduction. WELL: Loughborough University.

Davis, M. (1998) Rural household energy consumption: the effects of access to electricity - evidence from South Africa. Energy Policy 26, 207-17.

De Wet, T., Mathee, A. and Barnes, B. (2001) Anthropology and epidemiology: a case study of health and environment in Alexandra, Johannesburg. Africanus 31, 75-106.

Department of Minerals and Energy (2001) National electrification programme (NEP) 1994-1999 summary evaluation report. Pretoria: DME

Department of Minerals and Energy (2004) Integrated Household Clean Energy Strategy. Pretoria: DME.

Department of Minerals and Energy (2006) Digest of South African Energy Statistics. Pretoria: DME.

Dherani, M., Pope, D., Mascanheras, M., Smith, K. R., Weber, M., Bruce, N. G. (2008) Indoor air pollution from unprocessed solid fuel use and pneumonia risk in children aged under five years: a systematic review and meta-analysis. Bulletin of the World Health Organization 86, 390-398

Dudley, L., Hussey, G., Huskissen, J. and Kessow, G. (1997) Vitamin A status, other risk factors and acute respiratory infection morbidity in children. SAMJ 87, 65-70.

Engelbrecht, J.P., Swanepoel, L., Chow, J.C., Watson, J.G. and Egami, R.T. (2001) $\mathrm{PM}_{2.5}$ and $\mathrm{PM}_{10}$ concentrations from the Qalabotjha low-smoke fuels macroscale experiment in South Africa. Environmental Monitoring and Assessment 69, 1-15.
Ezzati, M., Bailis, R., Kammen, D., Holloway, T., Price, L., Cifuentes, L., Barnes, B.R., Chaurey, A. and Dhanapala, K. (2004) Energy management and global health. Annual Review of Environment and Resources 29, 383-419.

Ezzati, M. and Kammen, D. (2002) The health impacts of exposure to indoor air pollution from solid fuels in developing countries: knowledge, gaps, and data needs. Environmental health perspectives 110, 10571068.

Ezzati, M., Mbinda, B.M. and Kammen, D.M. (2000) Comparison of emissions and residential exposure from traditional and improved cookstoves in Kenya. Environ. Sc. Technol. 34, 578-583.

Goldemberg, J. (2004) Rural energy in developing countries. New York: UNDP, UNESCA \& WEC.

Kirkwood, B., Gove, S., Rogers, S., Lob-Levyt, P., Arthur, P. and Campbell, H. (1995) Potential interventions for the prevention of childhood pneumonia in developing countries: a systematic review. Bulletin of the World Health Organization 73, 793-8.

Kossove, D. (1982) Smoke filled rooms and lower respiratory disease in infants. South African Medical Journal April, 622-24.

Mathee, A., Röllin, H. and Bruce, N. (2000) Electricity and health. Johannesburg: MRC.

Matzopoulos, R., Jordaan, E. and Carolissen, G. (2006) Safety issues relating to paraffin usage in Eshane, Kwazulu- Natal. Journal of Energy in Southern Africa 17, 4-9.

Mehta, S. and Shahpar, C. (2004) The health benefits of interventions to reduce indoor air pollution from solid fuel use: a cost-effectiveness analysis. Energy for sustainable development 8, 53-59.

Moya, J., Bearer, C.F. and Etzel, R.A. (2004) Children's behaviour and physiology and how it affects exposure to environmental contaminants. Paediatrics 113, 9961006.

Mtango, F.D.E., Neuvians, D., Broome, C.V., Hightower, A.W. and Pio, A. (1992) Risk factors for deaths in children under 5 years old in Bagamoyo District, Tanzania. Trop. Med. Parasitol. 43, 229-233.

Muller, E., Diab, R.D., Binedall, M. and Hounsome, R. (2003) Health risk assessment of kerosene usage in an informal settlement in Durban, South Africa. Atmospheric Environment 37, 2015-2022.

Murray, C.J.L. and Lopez, A.D. (1997) Global mortality, disability, and the contribution of risk factors: Global Burden of Disease Study. The Lancet 349, 1436-42.

Nel, R., Terblanche, P., Danford, I., Opperman, L.B.P. and Pols, A. (2003) Domestic fuel exposure as a risk factors fro development of upper respiratory illnesses and lower respiratory illnesses in rural and urban communities. Clean Air Challenges 1993 (conference proceedings) paper $7,1-5$.

NEM (2004) National Environment Management: Air Quality Act, no. 39 of 2004. Cape Town: Republic of South Africa.

Norman, R., Barnes, B., Mathee, A., Debbie Bradshaw and the South African Comparative Risk Assessment Collaborating Group. (2007) Estimating the burden of disease attributable to indoor air pollution from 
household use of solid fuels in South Africa in 2000 , South African Medical Journal 97, 773-780.

Pande, J.N. (2000) Respiratory medicine in the tropics, Oxford: Oxford University Press.

Roberts, E. and Wentzel, M (2006) Household paraffin consumption in four areas: Benoni, Galashewe, Gugulethu and Lady Grey. Journal of Energy in Southern Africa 17, 23-26.

Röllin, H.B., Mathee, A., Bruce, N., Levin, J. and von Schirnding (2004) Comparison of indoor air quality in electrified and un-electrified dwellings in rural South African villages. Indoor Air 14, 208-216.

Sanyal, D.K. and Maduna, M.E. (2000) Possible relationship between indoor air pollution and respiratory illness in an Eastern Cape community. South African Journal of Science 96, 94-96.

Shackleton, C.M., Gambiza, J. and Jones, R. (2007) Household fuelwood use in small electrified towns of the Makana District, Eastern Cape, South Africa. Journal of Energy in Southern Africa 18, 4-9.

Schwartz, J. (2004) Air pollution and children's health. Paediatrics 113, 1037-1043.

Smith, K.R. (1987) Biofuels, air pollution and health, New York: Plenum Press.

Smith, K.R. (2002) Indoor air pollution in developing countries: recommendations for research. Indoor Air 12, 198-207.

Smith, K.R., Apte, G.M., Yuqing, M., Wongsekiarttirat, W. and Kulkarni, A. (1994) Air pollution and the energy ladder in Asian cities. Energy 19, 587-600.

Smith, K.R., Samet, J.M., Romieu, I. and Bruce, N. (2000) Indoor air pollution in developing countries and acute lower respiratory infection in children. Thorax 55, 518-532.

Statistics South Africa (2003) Census in Brief 2001, 2edn. Pretoria: South African government.

Statistics South Africa (2004) Census 2001: Primary Tables 1996-2001 Compared. Pretoria: Statistics South Africa.

Surridge, A.D., Kgobane, K.B. and Chauke, G.R. (2005) Strategy to combat the negative impacts of domestic coal combustion: Basa Njengo Magogo. Clean Air Journal 14, 13-16.

Terblanche, A.P., Opperman, L., Nel, C.M. and Nyikos, H. (1993) Exposure to air pollution from transitional household fuels in a South African population. $J$ Expo Anal Environ Epidemiol 3, 15-22.

Terblanche, A.P., Opperman, L., Nel, C.M., Reinach, S.G., Tosen, G. and Cadman, A. (1992) Preliminary results of exposure measurements and health effects of the Vaal Triangle Air Pollution Health Study. South African Medical Journal 81, 550-6.

Terblanche, P. (1998) Vaal Triangle air pollution and health study. Pretoria: MRC.

The World Resources Institute (1998) World resources: a guide to the global environment 1998-99.

Thomas, E.P., Seager, J.R., Viljoen, E., Potgieter, F., Rossouw, A., Tokota, B., McGranahan, G. and Kjellen, M. (1999) Household Environment and Health in Port Elizabeth. Cape Town: MRC

Victora, C.G., Kirkwood, B.R., Ashworth, A., Black, R.E.,
Rogers, S., Sazawal, S., Campbell, H. and Gove, S. (1999) Potential interventions for the prevention of child hood pneumonia in developing countries: improving nutrition. American Journal of Clinical Nutrition 70, 309-20.

Victora, C.S., Fuchs, S.C., Flores, J.A.C., Fonseca, W. and Kirkwood, B. (1994) Risk factors for pneumonia among children in a Brazilian metropolitan area. Paediatrics 93, 977-985.

von Schirnding, Y., Bruce, N., Smith, K.R., BallardTremmer, G., Ezzati, M. and Lvovsky, K. (2002) Addressing the impact of household energy and indoor air pollution on the health of the poor. Geneva: World Health Organisation.

von Schirnding, Y.E.R., Yach, D., Blignaut, R. and Mathews, C. (1991a) Environmental determinants of acute respiratory symptoms and diarrhoea in young coloured children living in urban and peri-urban areas of South Africa. SAMJ 79, 457461

von Schirnding, Y.E.R., Yach, D. and Klein, M. (1991b) Acute respiratory infections as an important cause of deaths in South Africa. South African Medical Journal 80, 79-82.

WEC \& FAO (1999) The challenge of rural energy in developing countries. London: World Energy Council.

Wesley, A.G. and Loening, W.E.K. (1996) Assessment and 2-year follow-up of some factors associated with severity of respiratory infections in early childhood. SAMJ 86, 365-368.

Wichmann, J. and Voyi, K.V.V. (2005) Air pollution epidemiological studies in South Africa - need for freshening up. Reviews on Environmental Health 20, 265301.

Wichmann, J. and Voyi, K.V.V. (2006a) Impact of cooking and heating fuel use on acute respiratory health of preschool children in South Africa. The Southern African Journal of Epidemiology and Infection 21, 4854.

Wichmann, J. and Voyi, K.V.V. (2006b) Influence of cooking and heating fuel use on 1-59 month old mortality in South Africa. Maternal Child Health 10, 553-561.

World Health organization (2007) Indoor air pollution: national burden of disease estimates. Geneva: WHO.

Zwi, S., Davies, J.C.A., Becklake, M.R., Goldman, H.I., Reinach, S.G. and Kallenbach, J.M. (1990) Respiratory health status of children in the eastern Transvaal highveld. SAMJ 78, 647-653.

Received: 15 June 2008 